\title{
Adding ordinary lathe chuck wrench safety interlock device and the necessity of using effect
}

\author{
Dachuan Chen ${ }^{1}$ \\ ${ }^{1}$ School of North China Electric Power University, Hebei 071000, China; \\ a2785293432@qq.com
}

Keywords: Ordinary lathe,Chuck wrench interlock device, The need for.

\begin{abstract}
With the continuous development of science and technology, people to the security requirement is more and more prominent in mechanical production. There are some problems in the traditional lathe machining operations. Main show is safe with facilities not perfect, the operation personnel check does not reach the designated position, equipment structure of the chaos caused by the wrench failure and so on. From the above case, ordinary lathe chuck wrench additional safety interlock device is necessary. So, in this paper, the safety accident in lathe chuck wrench problems, on the necessity of the interlock device installation and using effect are analyzed.
\end{abstract}

\section{Introduction}

In lathe processing operations, safety accidents often happen. From the perspective of the integrity of the accident, the operator can only on the basis of increasing security, rational planning of operating means, with the spirit of full work to deal with. For ordinary machine tool operation project, not only requires has skilled technical staff, also asked them to the machine under the premise of high speed to preset chuck wrench, when faced with the flexibility of processing.

\section{The analysis of the causes of common lathe chuck wrench fault}

\section{The subjective reason}

In the process of mechanical processing and production, chuck wrench accidents have occurred. From the subjective sense, is mainly caused by the operator itself. Operator can't flexible hold the handle, the staff to remove in device, chuck will be placed in practical operation in the form of the clutch handle. But the work is the premise of the chuck insert to remove wrench in a timely manner at the same time, the problem often appears in the process of take out a wrench. Handle is together with machine, non-standard and as a result of the operation personnel action is likely to touch the handle in time, cause the whole machine chuck phenomenon. In addition, the operator does not have effective cooperation is also the principal causes of accidents. To install and remove operation process should be closely linked to, at the same time of installation, remove the staff will be ready to related. Because there is no timely remove, machine will start the operation procedure, the position of the chuck will also indirectly changed, if go to the machine in the same plane, the situation is very dangerous. Above two cases are due to not skilled operator means, no good cooperation as a result of [1].

2. the objective reasons

Objective reason mainly appear on the machine itself. When ordinary machine tools into, there may be some mechanical parts operation connectivity is not strong. If mechanical part device installation failure, and this kind of problem and its tiny, so the general testing means cannot be identified. In this state, the clutch and handle the coordination will be relatively lower, the handle is easy to appear in operation process to stop, and then, the phenomenon of the chuck. In general, the 
operator is to optimize the wrench disassembly work, in order to ensure the insert won't appear the dysfunctional situation when chuck. If the chuck in a central location to stop operation, during operation control center in the current situation, popping phenomenon happens wrench, which threatens the safety of operating personnel [2].

\section{Ordinary lathe chuck wrench safety interlock device and the necessity of using effect}

\section{Add chuck wrench the necessity of safety interlock device}

From chuck wrench in the system structure of safety interlock device, its shell is very advanced. First of all, the shell is mainly based on "iron" as the carrier, at each end of the connection of repeated welding, to add the thickness. From the original $0.5 \mathrm{~mm}$ to $1 \mathrm{~mm}$ of existing design. System device inside a position limit switch, limiting switch function is mainly to supervise and control the operation process, monitor the operation of the machine tool the internal regularity of the spindle box. Restrictive total switch interface and a double warning device, can the system interface is formed on the projection, and with a color change to reflect the dangerous situation exists. If the light from green to red, explain the movement rule of chuck wrench presents the unstable state, remind the operator to check in a timely manner. From this aspect, the interlock device Settings to conduct supervision over the whole interface control on the basis of operations. Saved staff time and improve the established working efficiency. From the design principle of safety interlock device, its necessity is also very significant. Before chuck design, operations staff to inside the interlock device connected to a main control circuit, the other lines in tandem with the main controller. Using series of the basic path for installation of switches in management. On the switch design two often contact, the main point of contact is to check the circuit development of the lathe, and clear whether there is a disconnect or reclosing phenomena. In addition, the series of control center can also go deep into the system of internal, if the path the present regulation, are in a form of correct installation instructions wrench, reasonable inspection laid the foundation for operators.

2. Add the use effect of chuck wrench safety interlock device

The use effect of chuck wrench interlock device is also very prominent. First of all, the installation of the chuck interlock to ensure the security of the artifact removal. Operators in the chuck prior to installation, safety interlock device must be inserted into the wrench, and use the security start switch of coordination to make the disc. If there is no security system switch of the start, the clutch handle operation will not occur. For example: the CA6136 machine tool to be modified, the operator to insert the wrench in the safety device, click on the safety switch unit, the power of voltage, under the action of closing device maintenance. If the closure device connected, the safe operation of the machine tool. Program connect switch is depending on the internal spring, when the series main controller is not received the safety device to remind, the clutch handle will stop running. Coordinate system to chuck. Operating personnel under the safety equipment normal operation, can be planned to chuck wrench, flexible adjustment of the power program protection power. The detected danger immediately cut off the power supply [3]. The most important of all, in a series system installation department is also equipped with machine tools at the bottom of main power supply. Its role is to prevent some dust or is broken into the iron machine tools, iron into the power supply will be a short circuit breaker, and hurt the operator. While the safety interlock set to avoid the occurrence of the problem [4].

\section{Conclusions}

To sum up, chuck wrench safety device added to conventional machine tools for machine tool to form a protective effect, but also to ensure the personal safety of operators and make the operation behavior is more scientific and reasonable, have created favorable conditions for the stable operation of the machine. 


\section{References}

[1] Duan Xiangxiang. How to prevent the engine lathe turning processing when forget to remove the chuck wrench [J]. Journal of vocational education research, preceding 2010:110-111.

[2] paulraj a. Based on HNC - 210 - a design principle and technology of numerical control lathe improvement Application research [D]. Nanchang university, 2012.

[3] Gu Chunmei. Introduction to students in ordinary lathe operation occurs when the cause of the accident and its preventive measures .

[J]. Journal of the new curriculum (below), 2011, 05:58.

[4] Yu Mingxin, Hou Huaying. Introduction to the importance of ordinary lathe C6140E add safety lock. [J]. Journal of information science and technology, 2013, 58. 